\title{
Smart Dashboard Multimedia pada Sistem Informasi Akademik
}

\author{
Dina Fitria Murad ${ }^{1}$, Rohmatul Laily ${ }^{2}$, Michellia Yosaputra ${ }^{3}$ \\ Departemen Sistem Informasi, BINUS Online Learning, Universitas Bina Nusantara \\ e-mail: dmurad@binus.edu
}

Diterima: 15 Maret 2021; Direvisi: 06 Mei 2021; Disetujui: 17 Mei 2021

\begin{abstract}
Abstrak
Informasi yang tepat dan sesuai kebutuhan penggunanya menjadi sebuah kebutuhan di era milenial ini. Para pengguna system menginginkan informasi yang tepat guna secara cepat melalui sebuah laman pada situs. Hal tersebut melatarbelakangi tujuan penelitian ini yaitu mengembangkan dashboard sistem informasi yang smart dan sesuai dengan kebutuhan jurusan dan mahasiswa BINUS Online Learning. System yanag kami bangun dirancang menggunakan metode System Development Life Cycle dengan pendekatan waterfall dengan 4 diagram pada UML untuk pemodelan bisnis prosesnya, serta wawancara dengan mahasiswa dan perwakilan jurusan. Berdasarkan hasil analisis yang dilakukan pada sistem berjalan menggunakan SWOT diketahui bahwa untuk strategi SO perlu peningkatan kualitas LMS dengan merancang fitur-fitur yang belum tersedia, untuk strategi WO perlu merancang dashboard sesuai dengan kebutuhan mahasiswa dan jurusan, semntara itu untuk strategi ST membuat laporan perkuliahan sementara bagi jurusan selama sistem usulan belum atau sedang dirancang dan strategi WT meminta kritik dan saran kepada mahasiswa dan dosen atas performa LMS secara berkala dan terus mengembangkan LMS berdasarkan kebutuhan. Hasil analisis dimappingkan kedalam perancangan sistem informasi akademik berupa dashboard sistem informasi yang smart dan dapat membantu mahasiswa dalam mendapatkan informasi perkuliahan serta menghasilkan laporan yang sesuai dengan kebutuhan jurusan.
\end{abstract}

Kata kunci: SWOT, smart Dashboard, LMS, SDLC

\begin{abstract}
Accurate information and according to user needs is a necessity in this millennial era. System users want precise information quickly via a page on the site. This is the background of the purpose of this study is to develop a smart information system dashboard and in accordance with the needs of BINUS Online Learning majors and students. The system we built was designed using the System Development Life Cycle method with a waterfall approach with 4 diagrams on UML for modeling business processes, as well as interviews with students and department representatives. Based on the results of the analysis carried out on the running system using SWOT, it is known that for the SO strategy it is necessary to improve the quality of the LMS by designing features that are not yet available, for the WO strategy it is necessary to design a dashboard according to the needs of students and majors, meanwhile for the ST strategy it is necessary to make temporary lecture reports. for majors as long as the proposed system has not been or is being designed and the WT strategy asks students and lecturers for criticism and suggestions on the performance of the LMS periodically and continues to develop the LMS based on needs. The results of the analysis are mapped into the design of an academic information system in the form of a smart information system dashboard that can help students get lecture information and produce reports according to the needs of the department.
\end{abstract}


Keywords: SWOT, smart Dashboard, LMS, SDLC

\section{PENDAHULUAN}

LMS sebagai Sistem Informasi Akademik BINUS Online Learning dirancang oleh pihak BINUS sendiri dan digunakan sebagai media pembelajaran yang menghubungkan antara dosen dengan mahasiswa. LMS yang dapat diakses melalui www.ol.binus.ac.id memiliki halaman depan yang cukup sederhana namun informatif, yang memuat nama mahasiswa, pengumuman/notifikasi, mata kuliah aktif, serta IPK mahasiswa. LMS sering diperbaharui secara berkala agar dapat tetap memenuhi kebutuhan mahasiswa, dimana peminatnya semakin meningkat setiap tahunnya.

Berdasarkan hasil wawancara kami dengan mahasiswa BINUS Online Learning yang sebagian besar pekerja/karyawan, mereka memerlukan informasi yang cepat tanpa harus datang ke BINUS/BULC mengingat waktu mereka sudah banyak dihabiskan di tempat kerja, dan hal ini belum tersedia maksimal pada LMS dan hal ini dapat difasilitasi dengan adanya sebuah dashboard Sistem Informasi Akademik bagi mahasiswa dan jurusan yang dapat menampilkan informasi yang dibutuhkan dalam tampilan visual [1] sehingga mata manusia dapat menangkap informasi secara cepat dan otak manusia dapat memahaminya secara benar [2]. Oleh karena itu, penyajian informasi harus dirancang sebaik mungkin sehingga pengguna mudah dalam membaca serta memahami informasi tersebut. Sebagai contoh, bila seorang mahasiswa tidak memenuhi syarat skripsi karena ada mata kuliah yang tidak lulus, maka ia dapat menentukan keputusan dalam mengurus administrasi mata kuliah yang tidak lulus. Semakin cepat informasi yang diterima, maka semakin cepat juga dalam pembuatan keputusan dalam perkuliahan online ini.

Berbagai pemodelan dashboard dapat dirancang menyesuaikan kebutuhan user. Seperti pemodelan dashboard akademik yang menggunakan BI dapat digunakan sebagai referensi dalam menyediakan informasi untuk pengambilan keputusan strategis pada Perguruan Tinggi dengan menambahkan komponen KPI yang mengacu pada matriks penilaian akreditasi Sarjana (S1) BAN-PT [3], termasuk penerapan visualisasi informasi dengan menggunakan system dashboard pada data-data akademik sangat membantu pihak manajemen di dalam memonitor performa dan kualitas akademik dari perguruan tinggi yang dipimpinnya. Tidak hanya itu, dengan bantuan sistem dashboard, pihak manajemen dapat mengambil keputusan dengan cepat dan tepat. Sehingga dapat lebih meningkatkan kualitas perguruan tinggi secara umum [2], Sistem monitoring akademik dapat memberikan informasi mengenai mahasiswa, alumni, siswa baru, dosen, dan matakuliah, serta dapat menyajikan informasi persentase, skor, dan kesimpulan berdasarkan teknik perhitungan Buku VI (Matriks Instrumen Penilaian Akreditasi BAN-PT) [4], Aplikasi akademik dashboard dapat membantu orang tua dan siswa mengetahui sejauh mana pembelajaran yang dilakukan anaknya di sekolah. Tidak hanya itu, aplikasi membantu pihak sekolah dalam proses akreditasi sekolah dan mempermudah pengambilan keputusan untuk siswa yang mendapatkan nilai kurang baik [5] dan dapat menampilkan kinerja fakultas dalam indikatorindikator yang terbagi ke dalam empat bagian yaitu Pendidikan dan Pengajaran, Penelitian dan Pengabdian Masyarakat, Umum dan Perlengkapan, serta Kemahasiswaan dan Kerjasama [6].

Berdasarkan hal tersebut, penulis merancang sebuah sistem informasi yang menjadi salah satu fitur tambahan untuk mendukung LMS dalam bentuk dashboard dimana dashboard ini akan menampilkan sejumlah informasi terkait perkuliahan. Namun dikarenakan LMS saat ini sedang aktif digunakan pada sistem berjalan, penelitian ini tidak didukung untuk akses API ke LMS berjalan dan berdasarkan diskusi dengan perwakilan stakeholder disarankan untuk mengembangkan sistem secara independen yang nantinya akan diadopsi pada LMS.

Setelah melihat permasalahan yang ada, maka penulis merumuskan permasalahan menggunakan sebuah pertanyaan yaitu bagaimana merancang sebuah dashboard Sistem Informasi Akademik berbasis website yang sesuai dengan kebutuhan mahasiswa yang mengambil perkuliahan online di Universitas Bina Nusantara? 


\section{METODE PENELITIAN}

Penelitian ini menggunakan metode penelitian System Development Life Cycle [7] dengan pendekatan Model Waterfall (gambar 1). Penelitian ini menggunakan data dummy LMS yang dituangkan dalam sebuah rancangan sistem informasi berbasis website yang mengadopsi beberapa fitur pada LMS saat ini .

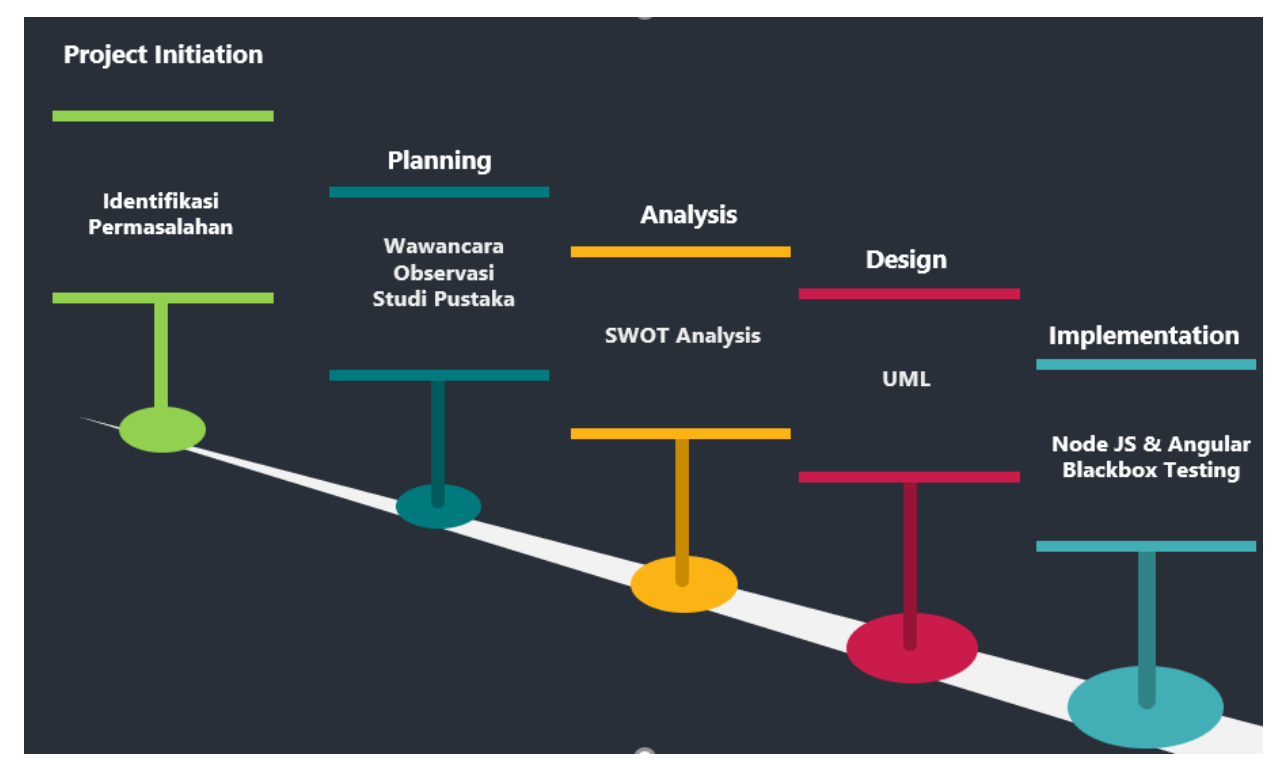

Gambar 1. Model Waterfall

\section{DISKUSI DAN HASIL}

\subsection{Analisis SWOT}

Analisis SWOT dilakukan untuk mengetahui kondisi system berjalan. Masing-masing indikator kekuatan (Strength), kelemahan (Weakness), peluang (Opportunity) dan ancaman (Threath) di analisis secara mendalam berdasarkan diskusi dan wawancara dengan stakeholder (gambar 2).

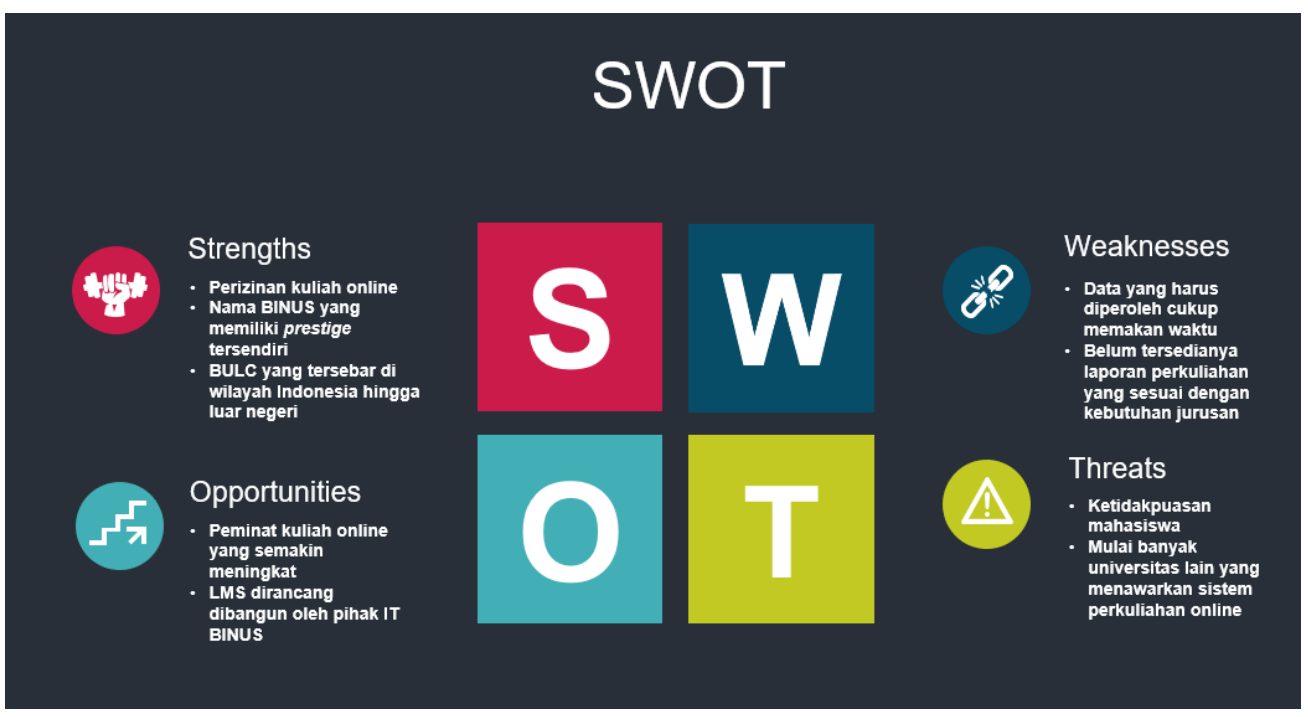

Gambar 2. Analisis SWOT 
Berdasarkan analisis SWOT dilakukan analisis silang dan menghasilkan strategi seperti pada table 1:

Tabel 1. Strategi silang SWOT

\begin{tabular}{ll}
\hline Strategi SO & Strategi WO \\
$\begin{array}{l}\text { Meningkatkan kualitas LMS dengan } \\
\text { merancang fitur-fitur yang belum tersedia. }\end{array}$ & $\begin{array}{l}\text { Merancang dashboard sesuai dengan } \\
\text { kebutuhan mahasiswa dan jurusan }\end{array}$ \\
\hline $\begin{array}{l}\text { Strategi ST } \\
\text { Membuat laporan perkuliahan sementara bagi }\end{array}$ & $\begin{array}{l}\text { Strategi WT } \\
\text { jurusan selama sistem usulan belum atau kritik dan saran kepada mahasiswa } \\
\text { sedang dirancang }\end{array}$ \\
& $\begin{array}{l}\text { dan dosen atas performa LMS secara berkala } \\
\text { kebutuhan }\end{array}$ \\
\hline
\end{tabular}

\subsection{Rancangan Dashboard} berikut:

Fitur dashboard yang dirancang untuk halaman mahasiswa memuat informasi dan fitur

1. Informasi terkait harapan IPK jurusan.

2. Informasi terkait IPK terakhir mahasiswa.

3. Informasi terkait status IPK mahasiswa, apakah sesuai dengan harapan jurusan atau tidak.

4. Informasi terkait nilai setiap mata kuliah yang diperoleh mahasiswa.

5. Informasi terkait IP dan IPK mahasiswa per periode.

6. Informasi terkait total sertifikat yang telah diperoleh mahasiswa.

7. Informasi terkait tahun lulus mahasiswa.

8. Informasi terkait tahun maksimal mahasiswa dalam mengikuti perkuliahan.

9. Informasi terkait mata kuliah yang tidak memenuhi standar nilai.

10. Informasi terkait status kelayakan mahasiswa untuk mengikuti mata kuliah thesis.

11. Informasi terkait 10 (sepuluh) mahasiswa dengan IPK tertinggi.

12. Fasilitas mengunduh lampiran dashboard

A. Halaman Jurusan

Fitur dashboard yang dirancang untuk halaman jurusan memuat informasi dan fitur berikut :

1. Informasi terkait rata-rata IPK untuk tiap angkatan

2. Informasi terkait angkatan dengan IPK terendah dan tertinggi

3. Informasi terkait 10 (sepuluh) mahasiswa dengan IPK tertinggi

4. Informasi terkait 10 (sepuluh) mahasiswa dengan IPK terendah.

5. Fasilitas mengunduh lampiran dashboard

6. Fasilitas untuk mengunduh laporan terkait hasil belajar mahasiswa yang berupa IPK.

7. Fasilitas untuk mengunduh laporan terkait mahasiswa yang tidak memenuhi standar nilai suatu mata kuliah.

8. Fasilitas untuk mengunduh laporan terkait status status kelayakan mahasiswa untuk mengikuti mata kuliah thesis.

\subsection{User Requirement}

Setelah melakukan observasi pada LMS dan wawancara terhadap mahasiswa (table. 2) dan pihak jurusan (table.3), maka didapat beberapa kebutuhan yang diperlukan guna membangun sebuah sistem yang diinginkan, kebutuhan-kebutuhan tersebut disusun sebagai berikut: 
Tabel 2 User Requirements untuk Halaman Mahasiswa

\begin{tabular}{|c|c|c|c|c|c|}
\hline No & Pertanyaan & Responden 1 & Responden 2 & Responden 3 & Kesimpulan \\
\hline 1 & $\begin{array}{lr}\text { Apa } & \text { harapan } \\
\text { anda terkait } \\
\text { dengan fitur IPK } \\
?\end{array}$ & $\begin{array}{l}\text { Dibuatkan } \\
\text { grafik yang } \\
\text { menunjukan } \\
\text { naik/turunnya } \\
\text { IPK dari periode } \\
\text { sebelumnya. }\end{array}$ & $\begin{array}{l}\text { Ditampilkan } \\
\text { pada halaman } \\
\text { utama. }\end{array}$ & $\begin{array}{l}\text { Tidak adanya } \\
\text { harapan dari } \\
\text { responden } \\
\text { terkait fitur } \\
\text { IPK }\end{array}$ & $\begin{array}{l}\text { Berdasarkan hal tersebut, } \\
\text { penulis merancang } \\
\text { grafik IPK mahasiswa } \\
\text { sehingga terlihat } \\
\text { naik/turunnya IP serta } \\
\text { IPK mahasiswa per } \\
\text { periode. }\end{array}$ \\
\hline 2 & $\begin{array}{lr}\text { Menurut } & \text { anda, } \\
\text { apakah } & \text { ada } \\
\text { tambahan fitur } & \text { fisa } \\
\text { yang } & \text { bisa } \\
\text { digunakan } & \\
\text { mahasiswa } & \\
\text { sehingga lebih } \\
\text { cepat dalam } \\
\text { mencari mata } \\
\text { kuliah yang } \\
\text { belum lulus? }\end{array}$ & $\begin{array}{l}\text { Ditambahkan } \\
\text { tools searching } \\
\text { atau menu baru } \\
\text { untuk } \\
\text { menampilkan } \\
\text { mata kuliah } \\
\text { yang belum } \\
\text { lulus }\end{array}$ & $\begin{array}{l}\text { Ditambahkan } \\
\text { tools filtering } \\
\text { atau bisa juga } \\
\text { diletakkan pada } \\
\text { halaman utama }\end{array}$ & $\begin{array}{l}\text { ditampilkan } \\
\text { pada halaman } \\
\text { utama. }\end{array}$ & $\begin{array}{l}\text { Berdasarkan hal tersebut, } \\
\text { penulis merancang menu } \\
\text { mata kuliah yang tidak } \\
\text { memenuhi standar nilai, } \\
\text { dimana menu ini } \\
\text { langsung menampilkan } \\
\text { mata kuliah yang tidak } \\
\text { memenuhi standar nilai } \\
\text { saja sehingga tidak } \\
\text { memerlukan tools } \\
\text { searching/filtering }\end{array}$ \\
\hline 3 & $\begin{array}{l}\text { Bagaimana cara } \\
\text { anda } \\
\text { mengetahui } \\
\text { bahwa anda } \\
\text { sudah } \\
\text { memenuhi } \\
\text { persyaratan } \\
\text { skripsi? }\end{array}$ & $\begin{array}{l}\text { Hanya } \\
\text { mengetahui } \\
\text { salah satu dari } 3 \\
\text { persyaratan. }\end{array}$ & $\begin{array}{l}\text { Responden } \\
\text { belum } \\
\text { mengetahui } \\
\text { persyaratan } \\
\text { karena belum } \\
\text { tersedia pada } \\
\text { LMS }\end{array}$ & $\begin{array}{l}\text { Hanya } \\
\text { mengetahui } \\
\text { salah satu dari } \\
3 \text { persyaratan. }\end{array}$ & $\begin{array}{l}\text { Berdasarkan hal tersebut, } \\
\text { penulis merancang fitur } \\
\text { status kelayakan } \\
\text { mengikuti mata kuliah } \\
\text { thesis, dimana tertampil } \\
\text { semua persyaratan yang } \\
\text { harus dipenuhi. }\end{array}$ \\
\hline 4 & $\begin{array}{l}\text { Bagaimana anda } \\
\text { melihat nilai } \\
\text { atau IPK anda } \\
\text { untuk periode- } \\
\text { periode } \\
\text { sebelumnya? }\end{array}$ & $\begin{array}{l}\text { Teridentifikasi } 2 \\
\text { proses untuk } \\
\text { mendapatkan } \\
\text { informasi } \\
\text { tersebut dan } \\
\text { waktu untuk } \\
\text { memilah-milah } \\
\text { informasi terkait } \\
\text { nilai. }\end{array}$ & $\begin{array}{l}\text { Responden } \\
\text { belum } \\
\text { mengetahui } \\
\text { cara untuk } \\
\text { melihat nilai } \\
\text { atau IPK dan } \\
\text { tidak pernah } \\
\text { cek nilai /IPK. }\end{array}$ & $\begin{array}{l}\text { Responden } \\
\text { belum } \\
\text { mengetahui } \\
\text { cara melihat } \\
\text { nilai atau IPK. }\end{array}$ & $\begin{array}{l}\text { Berdasarkan hal tersebut, } \\
\text { penulis merancang menu } \\
\text { yang berisikan nilai final } \\
\text { mahasiswa setiap mata } \\
\text { kuliah berserta grade } \\
\text { minimal yang harus } \\
\text { dicapai. }\end{array}$ \\
\hline 5 & $\begin{array}{l}\text { Apa harapan } \\
\text { anda terkait fitur } \\
\text { yang bisa } \\
\text { ditambahkan di } \\
\text { LMS yang bisa } \\
\text { memudahkan } \\
\text { mahasiswa? }\end{array}$ & $\begin{array}{l}\text { Dapat } \\
\text { ditampilkannya } \\
\text { nilai akhir } \\
\text { mahasiswa } \\
\text { beserta } \\
\text { minimum grade. }\end{array}$ & $\begin{array}{l}\text { Informasi } \\
\text { terkait mata } \\
\text { kuliah yang } \\
\text { tidak } \\
\text { memenuhi } \\
\text { standar nilai } \\
\text { dapat di unduh }\end{array}$ & $\begin{array}{l}\text { Diberikan } \\
\text { keterangan } \\
\text { status IPK } \\
\text { sehingga } \\
\text { mengerti apa } \\
\text { arti emoticon } \\
\text { senyum dan } \\
\text { sedih }\end{array}$ & $\begin{array}{l}\text { Berdasarkan hal tersebut, } \\
\text { penulis merancang fitur } \\
\text { unduh laporan dashboard } \\
\text { dalam bentuk PDF, } \\
\text { sehingga data tidak dapat } \\
\text { di edit. Lalu penulis juga } \\
\text { menambahkan informasi } \\
\text { terkait status IPK } \\
\text { mahasiswa. }\end{array}$ \\
\hline 6 & $\begin{array}{l}\text { Pengembangan } \\
\text { terkait fitur } e- \\
\text { certificate }\end{array}$ & $\begin{array}{l}\text { Ditampilkan di } \\
\text { halaman utama } \\
\text { terkait informasi } \\
\text { total } \quad e- \\
\text { certificate }\end{array}$ & $\begin{array}{l}\text { Ditampilkan di } \\
\text { halaman utama } \\
\text { terkait } \\
\text { informasi total } \\
\text { e-certificate }\end{array}$ & $\begin{array}{l}\text { Ditampilkan } \\
\text { di halaman } \\
\text { utama terkait } \\
\text { informasi } \\
\text { total } e \text { - } \\
\text { certificate }\end{array}$ & $\begin{array}{l}\text { Berdasarkan hal tersebut, } \\
\text { penulis merancang menu } \\
\text { yang menampilkan total } \\
\text { e-certificate yang } \\
\text { dimiliki mahasiswa. }\end{array}$ \\
\hline
\end{tabular}


Tabel 3 User Requirement halaman Jurusan

\begin{tabular}{cl}
\hline No & Kebutuhan Jurusan \\
\hline 1 & Menampilkan informasi rata rata IPK angkatan untuk pihak jurusan \\
2 & $\begin{array}{l}\text { Menampilkan informasi angkatan dengan IPK tertinggi dan rata rata ipk terendah untuk pihak } \\
\text { jurusan } \\
3\end{array}$ \\
$\begin{array}{l}\text { Menampilkan informasi terkait dengan } 10 \text { (sepuluh) mahasiswa dengan IPK tertinggi untuk } \\
\text { pihak jurusan }\end{array}$ \\
$\begin{array}{l}\text { Menampilkan informasi terkait dengan } 10 \text { (sepuluh) mahasiswa dengan IPK terendah untuk } \\
\text { pihak jurusan }\end{array}$ \\
$\begin{array}{l}\text { Digunakan jurusan untuk mengunduh lampiran dashboard } \\
6\end{array} \quad \begin{array}{l}\text { Digunakan jurusan untuk mengunduh laporan terkait hasil belajar mahasiswa yang berupa } \\
\text { IPK }\end{array}$ \\
$\begin{array}{l}\text { Digunakan jurusan untuk mengunduh laporan terkait mahasiswa yang tidak memenuhi } \\
\text { Digunakan jurusan untuk mengunduh status kelayakan mahasiswa untuk mengikuti mata } \\
\text { kuliah thesis }\end{array}$ \\
\hline
\end{tabular}

\subsection{Tampilan LMS}

A. Informasi terkait harapan IPK jurusan

Pada gambar. 3 terlihat bahwa informasi pertama yang ada di dalam dashboard mahasiswa adalah informasi terkait harapan IPK jurusan. Harapan IPK ini merupakan capaian IPK yang diharapkan pihak jurusan terhadap mahasiswa

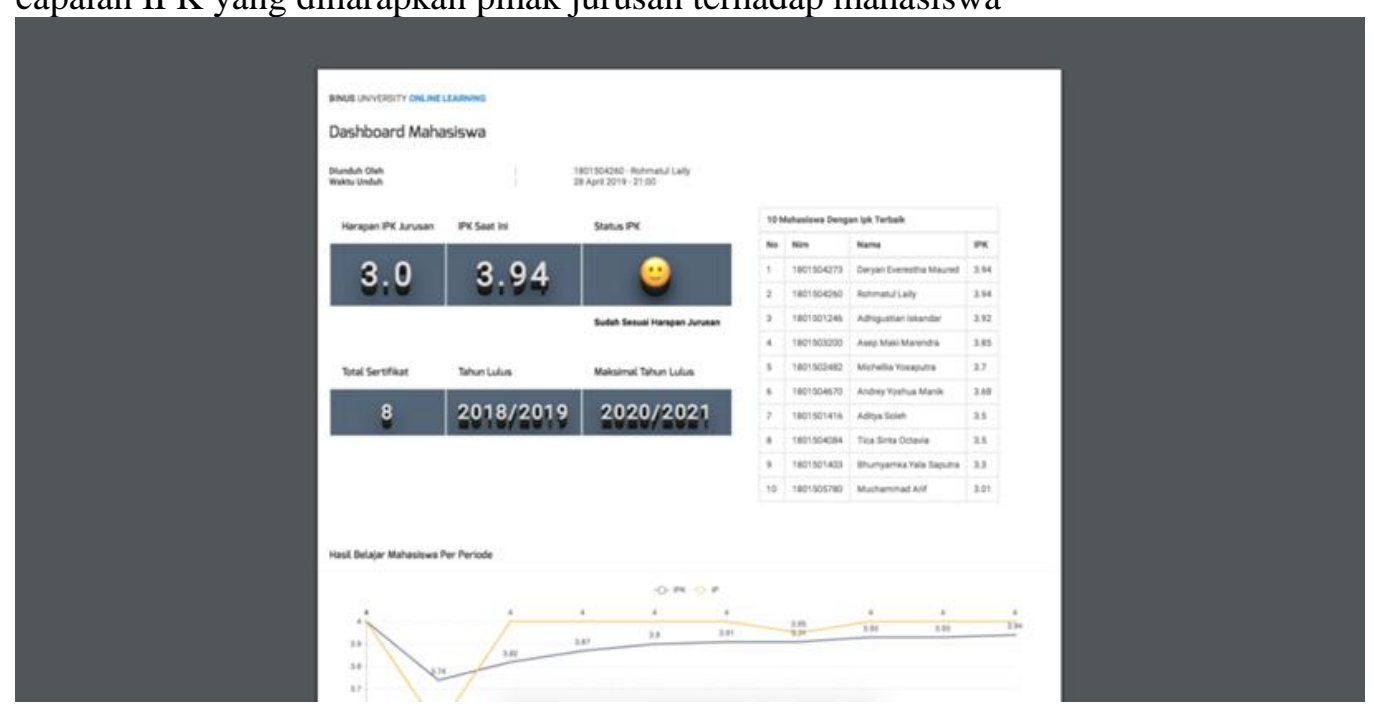

Gambar 3. Informasi terkait harapan IPK jurusan

B. Informasi nilai matakuliah

Pada gambar. 3 terlihat bahwa terdapat informasi didalam dashboard mahasiswa terkait nilai setiap mata kuliah yang diperoleh mahasiswa. Untuk melihat informasi tersebut mahasiswa harus klik button lihat nilai seperti gambar diatas. Selanjutnya mahasiswa bisa melihat nilai akhir setiap mata kuliah dalam bentuk tabel pada gambar 


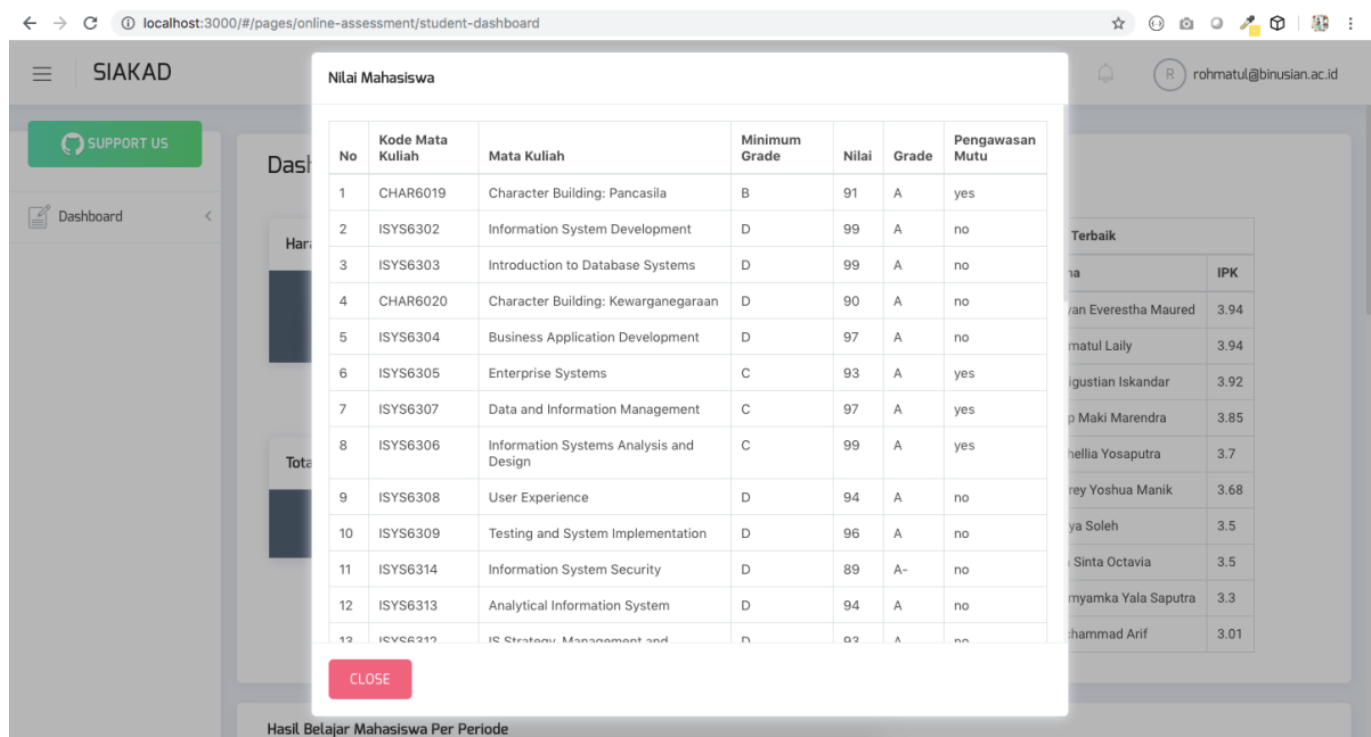

Gambar 4. Informasi nilai matakuliah

C. Informasi terkait IP dan IPK mahasiswa per periode

Selain itu, seperti terlihat pada gambar 3, dashboar juga menginformasikan terkait IP dan IPK mahasiswa per periode. IP dan IPK mahasiswa disajikan dalam bentuk grafik di gambar 5 .

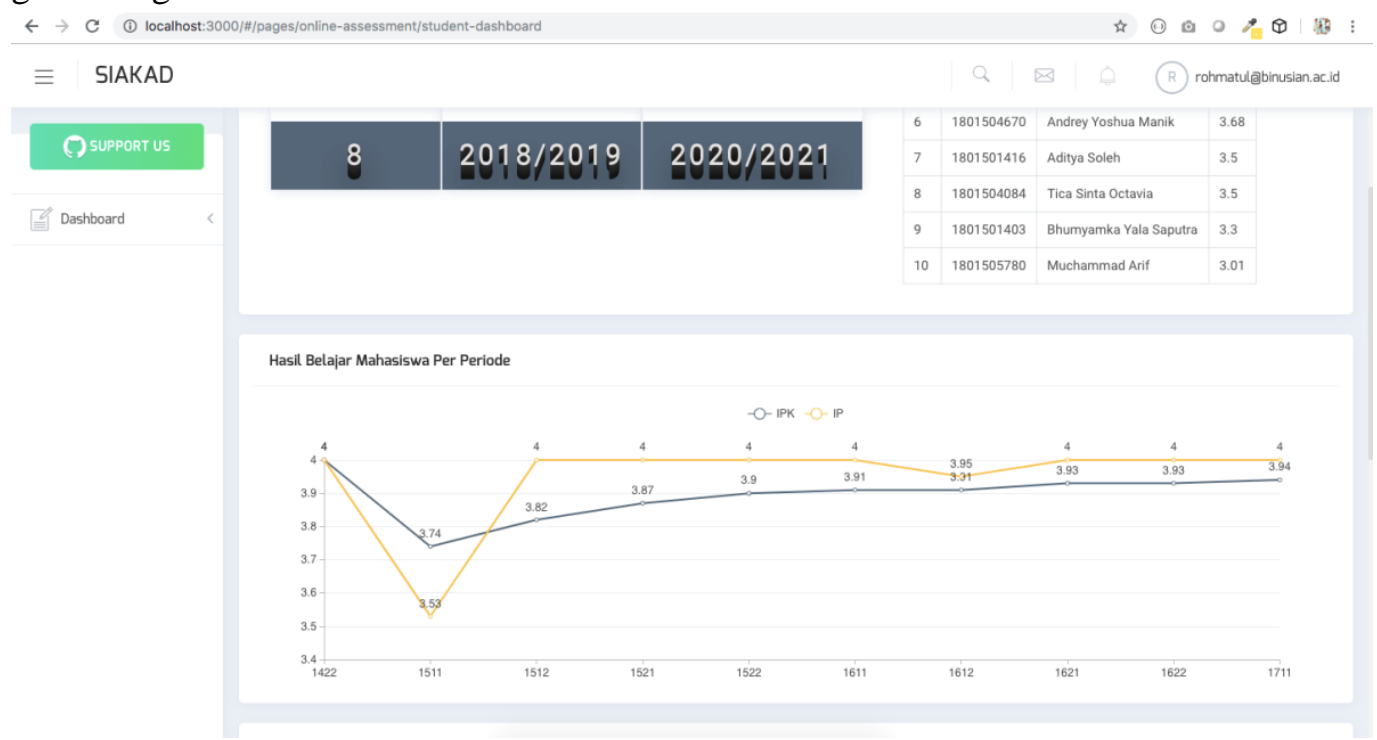

Gambar 5. Informasi IP dan IPK mahasiswa

D. Informasi nilai matakuliah yang tidak sesuai standarisasi kelulusan matakuliah

Agar mahasiswa dapat memonitor secara mandiri target kelulusan maka disediakan fasilitas terkait informasi nilai kelulusan yang dimapping dengan syarat minimal kelulusan sehingga mahasiswa dapat segera melakukan pengulangan matakuliah tanpa harus diingatkan oleh jurusan. 


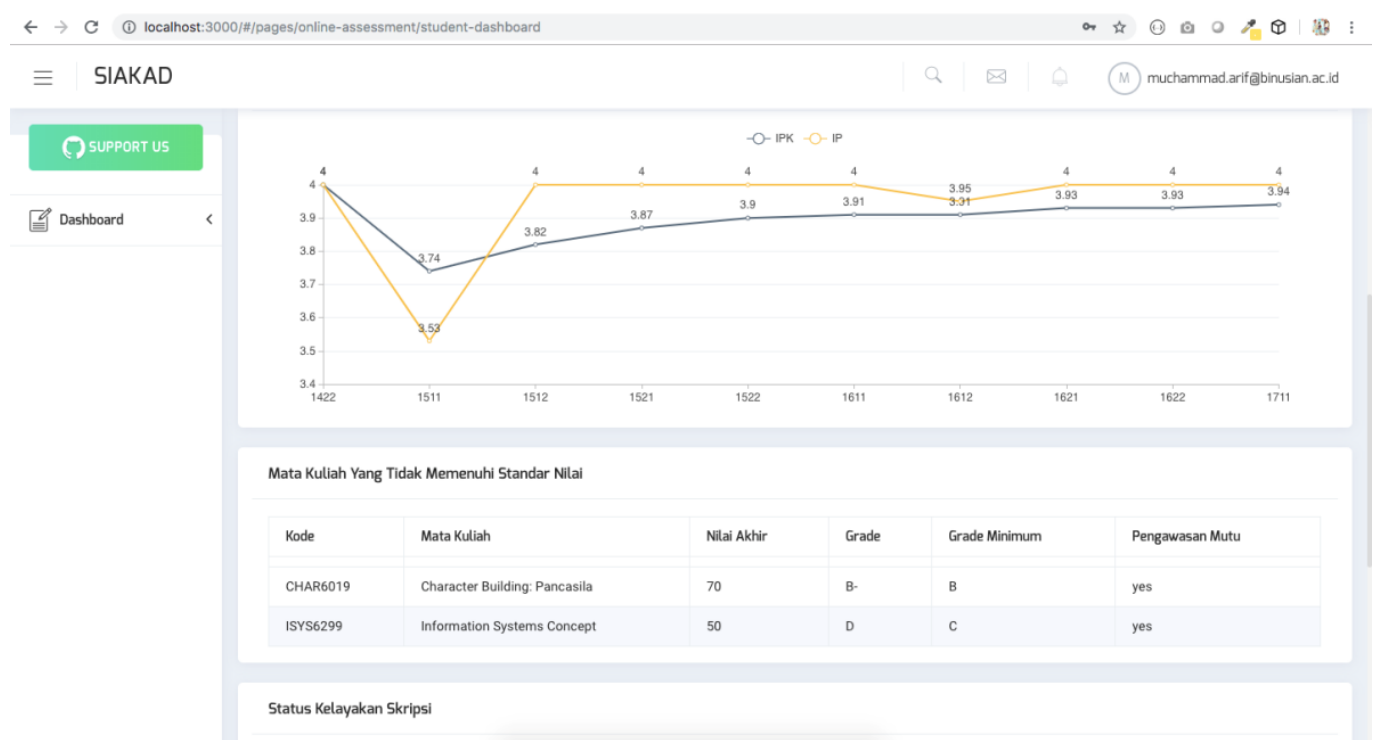

Gambar 6. Informasi nilai matakuliah yang tidak sesuai

E. Informasi Top 10 best

Untuk memotivasi mahasiswa yang belum mencapai target minimal serta memberikan apresiasi bagi yang memiliki nilai terbaik maka disediakan dashboard terkait 10 mahasiswa terbaik berdasarkan IPK mahasiswa berdasarkan view mahasiswa (gambar 7) dan view jurusan (gambar 8).

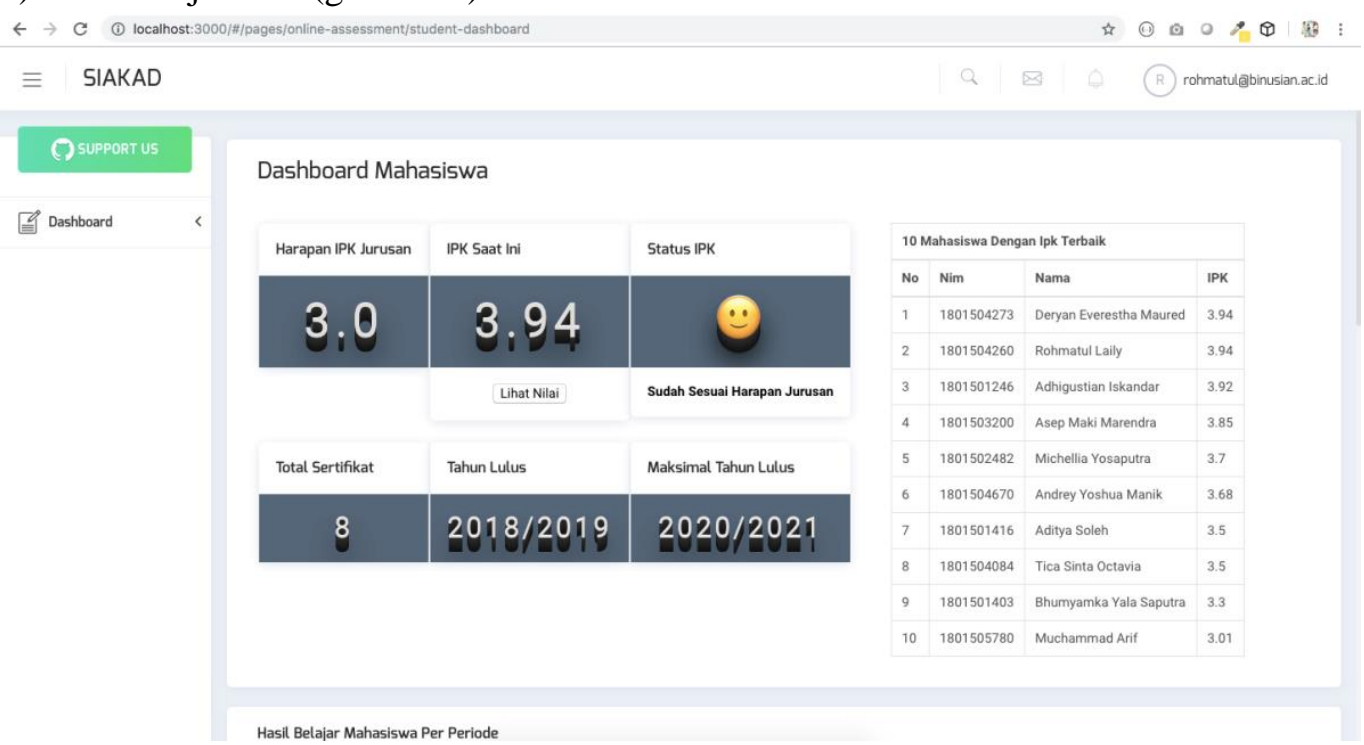

Gambar 7. Top 10 Best mahasiswa berdasarkan view mahasiswa 


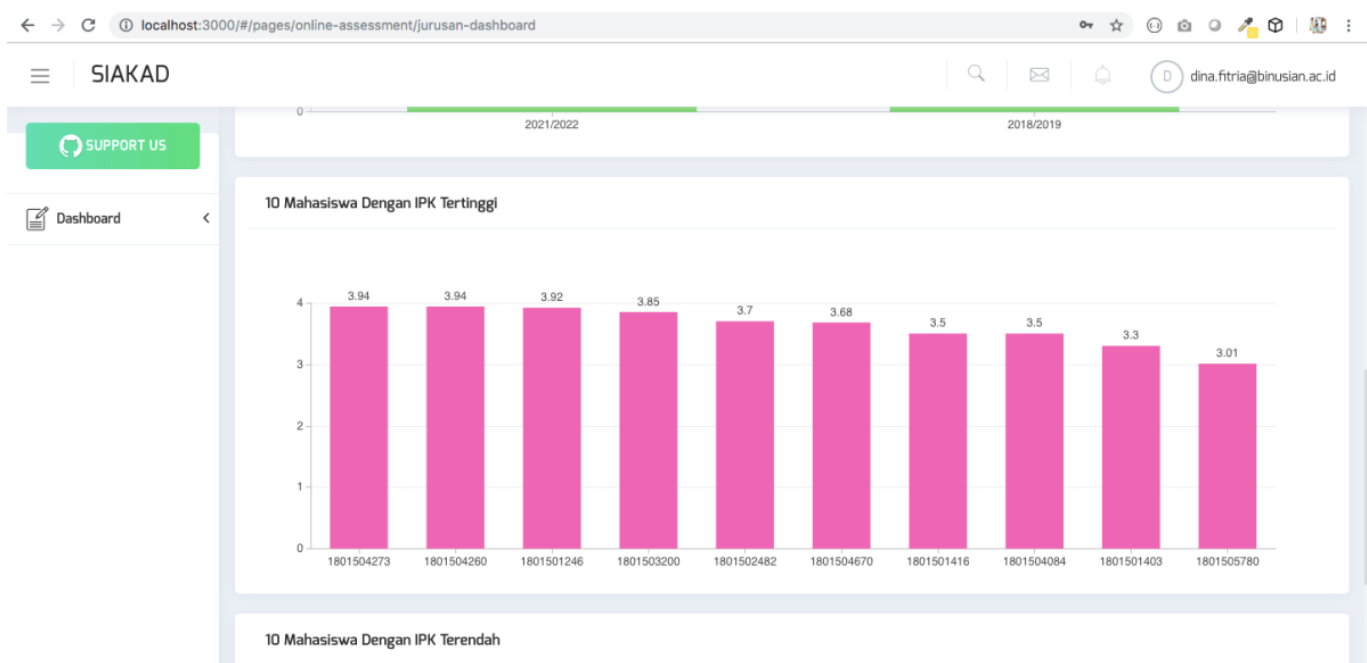

Gambar 8. Top 10 Best mahasiswa berdasarkan view jurusan

Dari sisi jurusan akan ditampilkan juga Top 10 Worst yaitu 10 mahasiswa yang perlu pembinaan terkait hasil belajarnya (gambar 9).

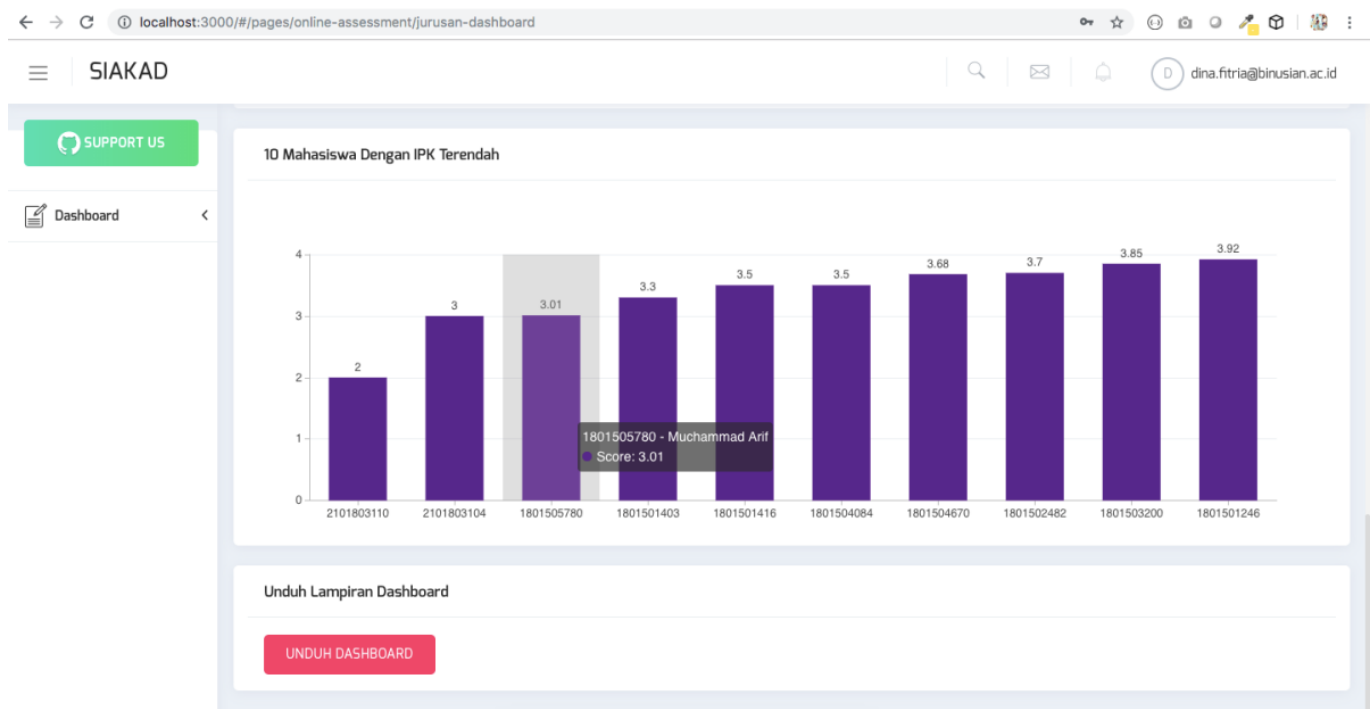

Gambar 9. Daftar 10 mahasiswa yang perlu binaan dari jurusan

Untuk mengetahui sejauhmana dashboard ini memberikan benefit kepada mahasiswa dan jurusan maka dilakukan interview sekaligus testing langsung dengan perwakilan mahasiswa beserta jurusan. Hasil akhir nya dicobakan data dummy sejumlah 4 semester transaksi pembelajaran mahasiswa dan menghasilkan data yang akurat $100 \%$. Berdasarkan diskusi tersebut diketahui, bagi mahasiswa maupun jurusan, system ini terbukti memberikan manfaat yang besar sehingga dapat direkomendasikan kepada bagian terkait untuk pengembangan lebih lanjut. 


\section{KESIMPULAN}

Secara umum, hasil Penelitian ini tidak mengalami kendala yang berarti selama proses awal hingga akhir. Permasalahan user dianalisis dengan baik melalui informasi dan tinjauan langsung pada LMS yang berjalan saat ini. Meskipun hanya menggunakan data dummy, namun karakter data yang digunakan sudah menyesuaikan data aslinya. Sehingga pada saat dilakukan testing dengan user hasilnya leboh maksimal. Agar system dapat bekerja dengan lebih baik maka disarankan untuk tetap dilanjutkan hingga dapat terintegrasi dengan system LMS saat ini.

\section{DAFTAR PUSTAKA}

[1] W. S. . S. J. and A. Cotgreave, The Big Book Of Dashboards: Visualizing Your Data Using Real-World Business Scenarios, 1st edition ed., Wiley, 2017.

[2] M. Ropianto, "Pemanfaatan Sistem Dashboard Pada Data Akademik Di Sekolah Tinggi Teknik (STT) Ibnu Sina Batam," Jurnal Teknik Ibnu Sina JT-IBSI, vol. 2, no. 2, 2017.

[3] N. Destiandi and A. Hermawan, "Business Intelligent Method for Academic Dashboard," bit-Tech, vol. 11, no. 20, pp. 11-20, 2018.

[4] N. K. D. F. Wantari, A. Y. Husodo and I. W. A. Arimbawa, "Rancang Bangun Sistem Monitoring Akademik Program Studi Teknik Informatika Universitas Mataram Menggunakan Data Warehouse," Journal of Computer Science and Informatics Engineering (J-Cosine), vol. 2, no. 1, pp. 17-23, 2018.

[5] S. Irawan and E. Sutomo, "Rancang Bangun Aplikasi Dashboard Akademik SMA SHAFTA Surabaya," Jurnal JSIKA, vol. 6, no. 1, pp. 156-162, 2017.

[6] R. I. Heroza, "Pemodelan Kebutuhan Sistem Dashboard Sebagai Indikator Kinerja Fakultas," KNTIA, vol. 4, 2017.

[7] J. W. Satzinger, R. B. Jackson and S. D. Burd, Introduction to Systems Analysis and Design: An Agile Iterative Approach, Course Technology, Cengage Learning, 2012. 